\title{
Las dinámicas de comercialización de frutas en la comunidad de Cochahuayco: oportunidades y retos para la agricultura familiar campesina
}

\author{
The dynamics of commercialization of fruits in the community of Cochahuayco: opportunities \\ and challenges for peasant family farming
}

Zoila Irene González Farroñay ${ }^{1}$ (iD) (8:

\begin{abstract}
Cómo citar
González Farroñay Z. I. (2021). Las dinámicas de Comercialización de frutas en la Comunidad de Cochahuayco: oportunidades y retos para la agricultura familiar campesina. Socialium, 5(2), 185-203 https://doi.org/10.26490/uncp.sl.2021.5.2.809
\end{abstract}

${ }^{1}$ Doctora en Medio Ambiente y Desarrollo Sostenible.

Universidad Nacional Federico Villarreal, Lima, Perú. zgonzález@unfv.edu.pe

Arbitrado por pares ciegos Recibido: $19 / 12 / 2020$ Aceptado: $20 / 06 / 2021$

\section{RESUMEN}

El objetivo del estudio fue identificar las dinámicas de comercialización de frutas en la comunidad de Cochahuayco: oportunidades y retos para la agricultura economía familiar campesina. El estudio considera a un sector de la población rural excluida y donde está ausente el Estado, para potenciar las capacidades de la población desde el punto de vista técnico y crediticio. Sin embargo, para ellos es un reto y usan estrategias que les permite sostenerse con la producción de sus frutas, las mismas que las transforman en derivados y van a las mesas de los consumidores; pero no en la intensidad que ellos quisieran. La investigación fue de corte cualitativo de nivel exploratorio descriptivo. Se seleccionaron 22 comuneros, donde se consideraron 3 directivos elegidos, por presentar indicadores de una lucha constante ante los retos que se le presentan para comercializar sus productos. Antes de aplicarse la entrevista, se realizó un Focus Group aplicado a los actores sociales para hacer la reconstrucción de las concepciones y vivencias de la situación estudiada esta reunión se llevó a cabo en el año 2019 y se ha recogido estos datos, pues con la pandemia no se ha podido viajar al lugar de los hechos, algunos datos se han validado a través de llamadas por teléfono celular. El resultado permitió arribar a que se identificaron tres formas de dinámicas de comercialización: 1. Comercialización Indirecta-Larga, 2. Comercialización Indirecto-Corto, y 3. Comercialización Directo Consumidor, muy frecuentes en sus actividades agrícolas, ello no les permite dinamizar la comercialización.

Palabras clave: dinámicas de comercialización; oportunidad; reto para la economía familiar.

\section{ABSTRACT}

The objective of the study was to identify the dynamics of fruit marketing in the community of Cochahuayco: opportunities and challenges for farming, peasant family economy. The study considers a sector of the rural population excluded and where the State is absent, to enhance the capacities of the population from a technical and credit point of view. However, for them it is a challenge and they use strategies that allow them to sustain themselves with the production of their fruits, the same ones that transform them into derivatives and go to consumers' tables; but not in the intensity that they wanted. The research was qualitative, exploratory and descriptive. 22 community members were selected, where 3 elected managers were considered, for presenting indicators of a constant struggle in the face of the challenges that are presented to them to market their products. Before applying the interview, a Focus Group applied to social actors was carried out to reconstruct the conceptions and experiences of the situation studied, this meeting was held in 2019 and this data has been collected, because with the It has not been possible to travel to the scene of the pandemic, some data has been validated through cell phone calls. The result allowed us to identify three forms of marketing dynamics: 1 . Indirect-Long Marketing, 2. Commercialization Indirect - Short and 3. Direct Marketing - Consumer, very frequent in their agricultural activities, this does not allow them to boost marketing.

Keywords: marketing dynamics; opportunity; challenge for the family economy. 


\section{Introducción}

Los comuneros de Cochahuayco, principalmente son agricultores y se dedican a la agricultura de frutos. Los cultivos principales son: manzana, membrillo palta y chirimoya en menor cantidad dedicada a su autoconsumo. Aparte de esto, también tienen una agricultura natural silvestre en algunos lugares pedregosos donde crece el membrillo. A su vez poseen una agroindustria a base de manzana y membrillo con los que elaboran el néctar de manzana, vinagre de manzana, sidra y mermelada. Las familias venden sus frutas con estrategias tradicionales que obedecen a las diferentes dinámicas de comercialización de productos frutales.

Los comuneros miembros de familias muy consolidadas, en su mayoría adultos y adultos mayores, conformaron organizaciones sociales que tuvieron el apoyo de entidades privadas, como el Centro Global para el Desarrollo y la Democracia, la Fundación CODESPA, el Centro de Investigación, Educación y Desarrollo (CIED) y Frutsana. El apoyo consistió en capacitación técnica (profesionales y técnicos que ayudan a mejorar la producción de las frutas y en la incorporación del valor agregado). Frente al precio muy barato de la fruta en chacra prefieren hacer vinagre, jugos, frugos, pero; es así que realizan este proceso de transformación de sus frutos. A su vez cuentan con una planta agroindustrial donde se encuentra maquinarias y diagramas con los pasos a seguir en la elaboración de néctares y vinagres, basados en la manzana y el membrillo; hoy está paralizada, se malogró una pieza y comprarla es muy caro.

Pero aprendieron y continúan sembrando frutales y utilizan mecanismos y estrategias comerciales vigentes en los territorios y localidades aledaños, ello hace necesario plantear una caracterización de estas dinámicas de comercialización de sus frutos como el membrillo, la manzana y el aguaymanto. Los procesos se realizan acercándose a cuidar el medio ambiente; sin embargo, es por intuición que lo hacen frente a la carencia de información al respecto. A pesar de ello lo hacen y es necesario por ser su única fuente de trabajo para la mayoría, ello les sirve de sustento para satisfacer necesidades prioritarias, de lo contrario sucumben en pobreza absoluta.

Los pobladores de Cochahuayco están organizados bajo la denominación de Comunidad. En la realidad peruana, se reconoce a estas formas de organización social mediante la Ley de Comunidades Campesinas, Ley $N^{\circ} 24656$, que, en su artículo 2 señala:

Las Comunidades Campesinas son organizaciones de interés público, con existencia legal y personería jurídica integradas por familias que habitan y controlan determinados territorios, ligadas por vínculos ancestrales, sociales, económicos y culturales, expresados en la propiedad comunal de la tierra, el trabajo comunal, la ayuda mutua, el gobierno democrático y el 
desarrollo de actividades multisectoriales, cuyos fines se orientan a la realización plena de las familias.

La Comunidad no solo se determina por su asentamiento geográfico, es el sentido de pertenecer a ella y por esto interactúan entre ellos con confianza. Según Ander-Egg (2005):

Una comunidad es una agrupación o conjunto de personas que habitan un espacio geográfico delimitado y delimitable, cuyos miembros tienen conciencia de pertenencia o de identificación con algún símbolo local y que interaccionan entre sí más intensamente que en otro contexto, operando en redes de comunicación, intereses y apoyo mutuo, con el propósito de alcanzar determinados objetivos, satisfacer necesidades, resolver problemas o desempeñar funciones sociales relevantes a nivel local. (pp. 33-34)

Alonso et al. (2004) precisan que, "la comunidad es un grupo social que comparte espacio donde la participación y cooperación de sus miembros posibilitan la elección consciente de proyectos de transformación dirigidos a la solución gradual y progresiva de las contradicciones potenciadoras de su autodesarrollo" (p.27). En este sentido la comunidad como organización permite a los comuneros tener una visión de su desarrollo.

Es relevante resaltar como se organiza la comunidad para su buen funcionamiento, así para Ramió (2012) "una forma de definir a las organizaciones es partir de la consideración que éstas son unas unidades sociales con unos objetivos particulares. Esta afirmación general se puede ir concretando, resaltando los elementos fundamentales que delimitan a las organizaciones" (p.7).

El motivo de este estudio es tener en cuenta que los productos agrícolas que se producen los auto consumen y el grueso de la producción apta para el consumo se comercializa. Según Caldentey y De Haro (2004), definen a la Comercialización Agrícola como "el proceso que lleva a los productos desde la explotación agraria hasta el consumidor" (p. 27).

Continuamos considerando otras definiciones sobre la comercialización, así:

El Instituto Interamericano de Cooperación para la Agricultura (IICA, 2018). Por su parte, afirma la comercialización es el "conjunto de funciones que se desarrollan desde que el producto sale del establecimiento de un productor hasta que llega al consumidor".(p.11) , a través de un mercado determinado. Es un mecanismo de coordinación para las transferencias e intercambios que realizan los diferentes agentes que participan en una cadena productiva.

Para la Universidad de Buenos Aires (UBA, 2017), la comercialización comprende un conjunto de funciones que se desarrollan desde que el producto sale del establecimiento de un productor hasta que llega al consumidor, a través de un mercado determinado. Es un mecanismo de coordinación para las transferencias e intercambios que realizan los diferentes agentes que participan en una cadena 
productiva. Entre las funciones de la comercialización destacan: comprar, vender, transportar, almacenar, estandarizar y clasificar, financiar, asumir riesgos y obtener información del mercado.

La finalidad es organizarse para procesar los frutos desde la cosecha y convertirlos en productos que lleguen a la población interna y a los turistas que visitan Antioquía y pasan a Cochahuayco; a ellos les ofrecen una gran variedad de productos como manzana delicia, manzana para el desayuno, las loncheras, manzanas deshidratadas, vinagre, mermeladas, frugos, jugos, bebidas y helados artesanales, pero son productos que no cuentan con registro sanitario.

La Dirección General de Salud Ambiental (DIGESA), organismo del Ministerio de Salud del Perú, es quien otorga la certificación; sin embargo, los pobladores de Cochahuayco que se dedican a sembrar los frutos no obtienen la certificación por falta de dinero para pagar los derechos, por ello solo ofrecen sus productos a los visitantes que deben ser consumidos a corto plazo. Los negociantes de Lima que tienen empresa compran a las comuneras el vinagre en significativas cantidades en barriles, pero sin registro, los intermediarios se encargan de obtener la certificación dando cumplimiento a los requisitos exigidos por DIGESA y le dan un valor agregado al vinagre además le ponen preservantes, cuentan con fecha de vigencia y caducidad de los productos y así se encuentran en los grandes supermercados a mayor precio. A las familias de la comunidad que se interesaron por obtener la certificación, se les dio información sobre las gestiones para lograrla, pero no cumplen con todos los requisitos. No cuentan con el dinero para pagar derechos.

Es además un impedimento el transporte público este juega un papel importante solo tres días a la semana cuentan con este, las carreteras son afirmadas de igual manera existe camino de trocha, los medios de transporte no permiten fomentar sus actividades comerciales a las provincias distritos y capital, por tanto, transportar sus productos les resulta muy caro.

La difusión se considera también un vehículo potencial para dar a conocer la existencia de sus productos, una página web, trípticos, revistas que promuevan a través de medios de comunicación información y sus productos se conozcan a nivel nacional. Por estas consideraciones no pueden competir con otros mercados, y algo característico; son las mujeres las que se encargan de trasmitir la oferta de sus productos y hoy le han delegado a sus hijos mayores, pero como migran a la capital no les interesa salvo a dos de ellos.

\section{Método}

Tipo de estudio. El problema fue investigado mediante la estrategia cualitativa. Para Taylor y Bodgan (1986), este método. "parte de los actores involucrados para describir, analizar e interpretar la realidad 
social (...) en donde se observan los escenarios y las personas desde una perspectiva holística" ( $p$. 19).

La investigación fue analizada desde el enfoque fenomenológico, definido por Martínez (1987) , como "el estudio de los fenómenos tal como son experimentados, vividos y percibidos por el ser humano, estudia una realidad cuya esencia depende del modo en que es vivida, percibida y sentida por cada persona, realidad (...) única y propia de cada cual" (p. 167). Por su parte, Barrantes (2000) enfatiza que el enfoque fenomenológico:

Analiza los fenómenos sociales desde la propia perspectiva del actor que lo experimenta, de manera que la visión que realmente importa es que las personas perciben como significativa, ya que se afirma que existe una red compleja de significados que definen una forma de entender la realidad, lo que está determinado por la posición que asuma el sujeto frente a ésta, en interacción con los demás. (p. 21)

El tipo de investigación es básica, descriptiva y transversal; con un enfoque cualitativo ya que se interpreta lo que cada uno de los actores sociales, que son parte del problema, sienten en relación a sus emociones, frustraciones, sus expectativas, respecto a cómo lograr empoderarse de otros mercados y hoy bajo la responsabilidad de los hijos, estos datos se recogieron aplicando entrevistas a profundidad que a través de preguntas abiertas, se obtuvieron los datos; de igual manera se consideró fuentes primarias y secundarias las que proporcionaron información cuantitativa para un mejor análisis integral. Por otro lado, el nivel de la presente investigación, es descriptivo-explicativa. Es descriptiva, por cuanto tiene la capacidad de seleccionar las características fundamentales del objeto de estudio y su descripción detallada de las partes, categorías o clases de dicho objeto; y, es explicativa, en la medida que se analizan las causas y efectos de la relación entre categorías.

Respecto al diseño de la investigación, describe la relación entre dos o más categorías, en un momento determinado, ya sea en términos correlacionales, o en función de la relación causa-efecto. Esta investigación tiene como propósito comprender e interpretar la relación entre las dinámicas de comercialización y las oportunidades y retos para la agricultura familiar campesina.

Población y muestra. La población considera a 98 pobladores de la comunidad organizados y como ellos se denominan comuneros está conformada por el presidente de la Comunidad campesina, el Teniente Gobernador; el Agente Municipal y las Organizaciones de Base Comedor Popular (Cochahuayco) y los pobladores.

Ello nos permitió tomar del tamaño de la población seleccionar a 3 de los integrantes de la directiva de la comunidad motivo de estudio; la elección de los individuos fue determinada por varones y mujeres adultos y ancianos (as) que son pobladores de la comunidad. 
Instrumentos de recolección de datos. En cuanto a los instrumentos de recolección, se aplicó una guía de entrevista semi estructurada a los representantes de la directiva y a los pobladores de la Comunidad de Cochahuayco.

Las Categorías que se estudiaron son las siguientes:

1. Las dinámicas de comercialización.

2. Oportunidades y retos para la agricultura familiar.

Procedimientos de la recolección de datos. Lo que nos conllevó al procesamiento de datos. Una vez seleccionada una de las fuentes de información se coordinó una reunión con los comuneros para obtener el consentimiento respectivo para aplicar las herramientas metodológicas. Las técnicas e instrumentos de recolección de información fueron los Planes de Desarrollo Local. De dicha información se seleccionaron a los comuneros varones y mujeres que tenían tres o más indicadores de agricultor de frutas. Para la segunda parte del estudio se desarrolló un focus group en los que se aplicaron técnicas expositivas ; dibujos y en la tercera y última parte del estudio se aplicó una entrevista semiestructurada a los directivos de la comunidad y a cada comunero y comunera que forma parte de la muestra seleccionada que en total son 22. A los comuneros se les explicó el objetivo del estudio con la finalidad de obtener su autorización para aplicar la entrevista de manera individual y si deseaban podían dar sus nombres y apellidos, de lo contrario se le asignará un seudónimo (elegido por ellos mismos), con el objeto de proteger su identidad y la confiabilidad de la información.

En el mes de febrero del 2020, fecha en que se realizó la última visita a la comunidad de Cochahuayco, la que se hizo con el propósito de coordinar con los directivos de la Comunidad la aplicación de las entrevistas, el que fue aceptado con la mejor predisposición y se contó con sus números de celulares o teléfono fijo de una de las comuneras para algún imprevisto o coordinación y así culminar con el recojo de datos. Cuando se realiza una investigación se considera situaciones imprevistas y tener estrategias para estos. De manera que en este año 2020 esta situación de la pandemia por el Covid-19, no se pudo viajar al lugar de los hechos, si fue posible aplicar la entrevista, vía teléfono. Además, algo muy importante es que antes de elaborar el proyecto se recogieron datos de la población acerca del tema, las mismas que ayudaron mucho en el desarrollo de la investigación.

Debido a la pandemia por Coronavirus la recolección de datos fue realizada por la investigadora con uno de los directivos de la comunidad

Aspectos éticos. La investigación, utiliza Técnicas e Instrumentos de Recolección de datos, esta se desarrolló con la debida confidencialidad y consentimiento. Además, del cumplimiento de los principios de honestidad, prudencia, responsabilidad y veracidad; los resultados generados del mismo son para fines estrictamente académicos y en pro del conocimiento. Por consiguiente, la presente investigación 
es resultado de las ideas surgidas por la investigadora, el consentimiento de los entrevistados para conocer y citar sus posturas y todo aquel apoyo literal es en cumplimiento de la propiedad intelectual (Disciplina del derecho encargada de regular la protección de las creaciones de la mente humana) y los derechos de autor, en concordancia con el Decreto Legislativo $N^{\circ} 822$, Ley sobre el derecho de autor.

\section{Análisis de datos}

\section{Dinámicas de Comercialización}

Al adentrarnos en lo que dicen las comuneras respecto a las Dinámicas de Comercialización, conseguimos manifestaciones como las que siguen, al preguntarles sobre lo que ellas conocen del tema y manifestó una de ellas:

“No, en verdad no, los comercializamos porque así vimos como lo hacían nuestros padres fue algo que aprendimos mirando y ellos nos recomendaban".

"Sí, las que uno conoce como venderles a los turistas que nos visitan lo hemos aprendido por nosotras mismas nadie nos enseñó en un libro".

María (comunera de 28 años de edad)

Entre los elementos que surgen, está el desarrollo de la comercialización con fuertes deficiencias en cuanto a la forma de vender sus productos y en particular de los frutos transformados dirigidos a clientes que esperan los visiten. Encontrando múltiples indicadores de esas carencias, como los que podemos observar a continuación, cuando se les pregunta sobre las formas de ¿cómo hacer la comercialización para vender sus frutas y derivados en otros mercados y no solo en las ferias en Cochahuayco, asimismo para vender a los grandes supermercados como Plaza Vea.

Sobre esto sí, incluso eso pregunté a una clienta que nos visitó de Lima y que tenía un negocio, ella vende de manera parecida a como yo hago la diferencia es que yo vendo frutas y mermeladas y lo hago como ella ve, la venta es directa y le hice el comentario, que también vendo a intermediarios, pero me pagan muy barato y ella me dijo: no, lo que vendo es ropa al por mayor, pero yo pensaba eso, que era la idea que yo tenía sobre la forma de vender al por mayor.

\section{Identificación de las dinámicas de comercialización}

Al preguntarles si conocen otras formas de comercializar sus frutas, responde:

“No, no lo conozco ¿̇a qué se refiere? No, no lo conozco esas formas. No, no aquí no porque aquí los clientes vienen a comprar eso lo vemos todos los días especialmente los fines de semana, sábado y domingo". 
Se percibe de entrada, un notorio desconocimiento del tema por todos los comuneros que comercializan los frutales y sus derivados, lo que resulta preocupante considerando que se atienden a clientes, turistas, intermediarios y que requerirían por la misma razón un conocimiento mínimo de otras dinámicas sobre cómo comercializar dentro de la comunidad y fuera de ella, para así, ser capaz de tomar decisiones que lo lleven a emprender actividades de comercialización acorde a los requerimientos del consumidor y del cliente, todo esto se sustentan en las teorías actuales sobre las dinámicas de la comercialización, como bien puede ser la teoría de las dinámicas de comercialización y citamos las que se han identificado :

\section{a) Comercialización Indirecta- Larga}

Esta forma de comercialización se caracteriza porque la primera transacción que realiza el productor es directamente con un intermediario, el cual se encarga de acopiar la producción para posteriormente venderlo a un nuevo agente de intermediación, sin que este sea el consumidor final.

Esto sucede tanto con la venta de manzana y membrillo, sobre todo el vinagre el agricultor vende a los intermediarios, a los vendedores del mercado de frutas de Lima, en la chacra los agricultores seleccionan, embalan y etiquetan los frutos, grandes, medianos y pequeños en cajas diferentes y de acuerdo a ello les asignan el precio, los frutos grandes tienen el mayor precio. Los intermediarios exigen frutos de primera calidad, pues los venden a los mayoristas y estos finalmente al consumidor en las tiendas y los mercados de Lima. Son las Expresiones recurrentes

Tenemos que vender nuestra fruta, la manzana el membrillo principalmente lo que nos queda porque es chiquito es para nuestro consumo, sino se nos pudre y perdemos, es dinero que no se puede votar, tenemos que alimentar a nuestros hijos, nuestra familia sino de que vivimos somos agricultores esto es lo sabemos hacer, el vinagre dura más y lo vendemos por litros en tanques de plástico.

manifiesta Norma (33 años de edad)

La respuesta recurrente en los comuneros estudiados, es que la comercialización es su trabajo en el día a día una vez que se cosechan las frutas.

Los comuneros y comuneras sostienen que ser agricultor es bueno y es favorable para sus vidas a nivel físico (los mantiene activos, casi no se enferman) a nivel económico no tienen excelentes ganancias, pero les permite sostener a su familia. Y son conscientes que les falta mayor capacitación técnica para mejorar la transformación de las frutas y ver otras formas de comercializar sus productos. Por esto precisa:

Nosotras somos las primeras en arreglar los puestos de exposición de las frutas, los vinagres, las mermeladas todos nuestros productos porque los varones no lo hacen, ellos están en las 
chacras y nosotras somos las que vendemos, nos va mejor que a los hombres no venden como las mujeres.

Narra Andrea, (comunera de 35 años de edad)

La comercialización de alimentos en las ferias que las mujeres organizan, arman sus mesas, kioskos y exponen sus productos, para iniciar la venta En este estudio se describe que la comercialización no se reduce a una simple transacción económica sino que tiene complejas influencias culturales y sociales. Por ejemplo, que la mayoría de las consumidoras sean mujeres favorece una comunicación horizontal con las vendedoras, del mismo género.

\section{b) Comercialización Indirecto - Corto}

Esta forma se caracteriza por tener una cadena de comercialización más sencilla en relación con el anterior, presenta mayores facilidades para el productor, ya que le permite articularse de manera directa a ellos, que de una u otra forma se vinculan con un minorista, para posteriormente enlazarse al consumidor final. El producto pasa por menos agentes de comercialización hasta llegar al consumidor final. Para esto el comunero productor ha tenido que asociarse, darles un valor agregado a sus productos, obteniendo así una mayor competitividad al momento de ofertarlos.

De igual manera venden desde la chacra a comuneros del lugar ellos los transformen en sus derivados y los venden a un intermediario, aquí radica el problema, en el caso del Vinagre que no cuenta con Registro Sanitario, el intermediario les compra el $80 \%$ de la producción en barriles, en Lima este lo envasa en botellas de medio litro o un litro y los vende a las tiendas al por mayor, para su consumo, pero este producto si cumple con los requisitos que exige un producto de calidad, es decir el Registro Sanitario, el Código de barras y la vigencia del producto. Por todo ello, el precio se eleva cuando va finalmente al consumidor.

Vender nuestras frutas, nos dejan una ganancia si lo hacemos todo el día, hasta la noche, pero el vinagre lo hacemos en la Planta de allí lo recogen y lo vendemos sacando nuestra ganancia, ni muy barato ni muy caro, así lo podemos vender y tener más pedido, tenemos algunos clientes fijos que nos compran al por mayor. Ya ellos lo venden a los que consumen, porque tienen el Registro Sanitario.

Dice María, de 42 años de edad.

\section{c) Comercialización Directo - Consumidor}

Este tipo de comercialización se caracteriza porque el productor se vincula de forma directa al consumidor final, sin depender de algún otro agente directo para su comercialización, es decir su primer agente de transacción es el consumidor final. La dinámica más interesante en esta es, que el mismo 
productor es el encargado de darle un valor agregado a su producto para ser ofertado con mayor oportunidad a este agente, este valor agregado es: mejora la presentación, cantidad adecuada, producción orgánica, entre otros.

Para vender los derivados de las frutas prestan Razón Social a otros microempresarios, a quien le pagan un porcentaje de la venta Total, lo que significa que no es un precio justo el que reciben por sus productos; todo esto porque no le ponen empeño a su formalización, dicen no cuentan con dinero para pagar los derechos que les permita contar con Registro Sanitario, emitido por DIGESA, por ello no salen del círculo vicioso de la pobreza al Virtuoso. Así también ofrecen a los turistas tanto nacionales como extranjeros que visitan Cochahuayco, sus productos y ellos compran porque todo es artesanal por esto su consumo es más o menos significativo.

Hoy en día la comunidad no cuenta con redes para promocionar sus productos porque no tienen los servicios de telefonía, internet que les permita difundir y tener información, del mismo modo no tienen a un especialista en Publicidad y Marketing para que los asesore en la planificación de la promoción de sus productos, difundirlo en el mercado de Lima pues este su objetivo. Al no contar con internet no pueden agilizar o paralizar sus transacciones económicas.

Por otro lado muestra las relaciones entre los productores y la autoridad local:

Al alcalde no le interesa poner estos servicios, es tan fácil ahora que venga movistar Claro, Entel y nos instale las antenas, pero no hace nada, nos tiene aislados, no sabemos que pasa en Lima (...) ni siquiera para que nuestros hijos estudien que ahora necesitan el internet, por eso tienen que ir a Lima allí si tienen.

Sra. Juana, comunera (28 años de edad)

Esta es la manifestación de una comunera respecto al papel que juega los medios de comunicación en su vida familiar y de la comunidad.

Al no hacer estudios de mercado para posesionarse en este, y no manejar precios para comercializarlos fuera de Cochahuayco, les dan un valor a las frutas considerando costos, lo que gastan en la siembra y cosecha, y así no pueden determinar el mejor precio para sus productos. Existe una condición ecológica a su favor, es que esta Comunidad cuenta con cerros rocosos donde crece el membrillo más saludable, no necesitan insecticidas, plaguicidas, fungicidas tienen agua de subsuelo y cada diez meses tienen los membrillos silvestres, este es un fruto orgánico, un membrillo de calidad por ello tiene mayor valor y su precio es alto en relación a los que siembran en la tierra.

Los precios de las frutas y sus derivados, en el mercado local no garantizan precios justos, al no contar con una comercialización colectiva local para el almacenamiento y la logística del transporte y el etiquetado de dichos productos. 


\section{Resultado}

\section{Dinámicas de Comercialización}

En primer lugar, cabe señalar el concepto del Grupo Temático Comercio con Justicia Honduras (2011). "la comercialización se ocupa de todo aquello que el mercado nos demanda o de aquello que los consumidores desean" (p.22). En el caso de las organizaciones campesinas, la comercialización debe servir para dar valor agregado a sus productos, atrayendo a los consumidores, y de esta manera incrementar la venta de los productos que siembran, generando ingresos para las familias campesinas. Cochahuayco es una comunidad del pueblo de Antioquía donde sus habitantes se dedican a la agricultura, siembran principalmente manzana y membrillo, las familias por lo general se organizan para trabajar dado que deben complementar sus ingresos y en ese sentido es que los varones van a las chacras a trabajar la siembra de las frutas y las mujeres se encargan de procesar en pequeñas plantas de la manzana elaboran Vinagre, del membrillo frugos, jugos, yogurt, zumos, a su vez siembran lúcuma, palta aguaymanto en menor cantidad

Esto significa que se debe vender sus productos en su localidad, a los turistas y al mercado de Lima, lamentablemente esto fracasó. Por ello el tema nos llevó a identificar las dinámicas de Comercialización tanto de las frutas y sus derivados teniendo como hallazgo que la dinámica frecuente para comercializar los frutos y sus derivados, especialmente el vinagre de manzana es: la Comercialización Directo Consumidor.

Este tipo de comercialización es la más usual donde la comunera productora se vincula de forma directa al consumidor final, sin depender de algún otro agente directo para su comercialización, es decir su primer agente de transacción es el consumidor

\section{Oportunidades y Retos para la agricultura familiar}

Una de las oportunidades relevantes que tienen al comercializar vinagre, mermeladas artesanales ,zumos pastas y frutos secos es que pueden ofrecer a los turistas tanto nacionales como extranjeros que visitan Antioquía y pasan a Cochahuayco; ese es su destino ,los visitantes les compran porque todo es artesanal sin conservantes, ni preservantes las mermeladas, los helados,cremoladas,yogurt ,queso ,leche entre otros, todos estos productos sin Registro sanitario esta es su gran debilidad .Esto no les permite competir con otros mercados a nivel nacional.

Han comercializado el vinagre de manzana vendiéndole a Plaza Vea, lo hacían a un buen precio respecto al del mercado local, pero las condiciones climatológicas no les ayudó por las lluvias es así que conservar las frutas les adicionó gastos imprevistos, como curarla, trasladarla motivo que originó elevar el precio de la manzana, por tanto, el precio del vinagre. A los productores les resultó cara la producción de vinagre y se vieron obligados a subir el precio, Plaza Vea no aceptó y cortaron relaciones económicas, hoy venden en mercados cercanos o en las ferias donde son invitados a exponer sus frutos y derivados, 
ellos entendieron que perdieron una de las oportunidades de entrar a los super mercados. Las comuneras son conscientes de sus debilidades no pueden competir con un mercado tan fuerte en Lima. En el día a día se les presentan retos de los cuales pueden salir airosos y lo hacen por vivencias, experiencias que les permiten solucionar estos, por ejemplo, no tenían envases para los helados donde se visualice su marca, mandaron hacer sus vasitos de diferentes tamaños y según este es el precio, las comuneras dicen por lo menos ya tiene la Marca de ellos.

De igual manera cuando han solicitado a DIGESA el registro sanitario, los funcionarios idóneos los visitaron para inspeccionar sus plantas y les recomendaron remodelar los ambientes donde artesanalmente hacen el vinagre, pusieron piso de cemento al ambiente, hicieron de cemento el lavadero de las frutas, compraron balanzas, manteles blancos para cubrir los barriles y asegurar que no entre ningún insecto ,mejoraron la iluminación artificial .Pocos son los que han invertido en hacer mejoras, algunos se acercan a tener en cuenta las medidas sanitarias según DIGESA, considerando que las frutas son parte de la dieta alimentaria y que repercute en la Salud de la población .

En la comunidad de Cochahuayco se aprecia diferentes formas de comercializar sus productos desde la chacra hasta los que son transformados. Y los ofrecen a un público variado por ello cada proceso de comercialización es diferente, dependiendo del producto a comercializar y del mercado al que está dirigido.

Lo que se puede rescatar es que tienen en cuenta las demandas de sus clientes, ellos les dan ideas y provienen de las necesidades del mercado.

Olga, comunera de 35 años de edad, manifiesta:

Algún día tendremos otras oportunidades de como comercializar nuestros productos en el mercado y hay que atender las necesidades de los clientes, por ello creo que hay que escuchar que quieren los clientes cuando les vendemos directamente, no somos empresarias apenas hemos empezado con el negocio de frutas y no pierdo la esperanza algún día ir a mercados grandes, no solo acá sino fuera de Cochahuayco.

De igual manera es imprescindible la organización, si bien es cierto no lo hacen todos los comuneros, lo hacen en familia.

\section{Organizaciones de agricultores, desarrollan las cadenas productivas para procesar frutas}

En la actualidad es la desorganización que no les ayuda a los integrantes de la comunidad, sobre todo a las mujeres que se dedican a elaborar los derivados de la manzana y el membrillo a diferencia de sus inicios estaban liderados por una comunera de 34 años (Sra. Jovita) quien organizó a las mujeres, con el objetivo de vender, comercializar sus productos no solo a los consumidores locales y turistas, sino a otros mercados. Hoy existe la desconfianza de quien fue su líder, esto no permitió la continuidad de un trabajo comunal organizado.

Según la Universidad de Buenos Aires (UBA, 2017); la UBA (2017) considera, la comercialización es: 
El conjunto de funciones que se desarrollan desde que el producto sale del establecimiento de un productor hasta que llega al consumidor, a través de un mercado determinado. Es un mecanismo de coordinación para las transferencias e intercambios que realizan los diferentes agentes que participan en una cadena productiva. Entre las funciones de la comercialización destacan: comprar, vender, transportar, almacenar, estandarizar y clasificar, financiar, asumir riesgos y obtener información del mercado. (p. 5)

Solo cuando visitan los turistas la comunidad se les presenta una excelente oportunidad para fortalecer la comercialización de los productos que siembran las familias agricultoras. Tienen la oportunidad de vender sus frutas queso, miel de abeja, polen, jugos, frugos, néctares, vinagre de manzana, aprovechan a exhibir todo lo que puedan en cuanto a productos comestibles. Los agricultores advierten que no pueden aprovechar algunas oportunidades porque necesitan programas e instrumentos enfocados a los agricultores familiares de pequeña escala de lo contrario solo favorecen a los agricultores de gran escala y con más recursos y son estos los que le sacan provecho.

Las comuneras agricultoras al tener una participación baja no pueden ayudar a los miembros de su familia a superar su situación más bien se invisibilizan.

Respecto a las cadenas productivas empieza con la producción de las frutas que siembran los varones y ellas las transforman, se puede decir que el último enlace en la cadena es primero el consumidor local y luego el consumidor indirecto. Desde luego esta cadena productiva la hacen cada vez que tienen las frutas para ser cosechadas, empiezan a ver a sus probables compradores tanto Directos como Indirectos, desde luego ellos desconocen que es todo un trabajo que técnicamente debe ser elaborado, utilizar estrategias en caso se presente un imprevisto, lo hacen por impulso, por voluntad, pero no como un proceso técnicamente planificado.

Un aspecto casi ausente en la comunidad es la capitación lo hacen por cuenta propia, tienen que gastar su dinero de manera particular y para ello envían a sus hijos a Lima a recibir esta información para luego aplicarla a los procedimientos de transformación de las frutas.

\section{Asesoría y capacitación técnica}

Inicialmente en los años 1993 tuvieron la presencia de una ONG que les expuso la idea de este proyecto: procesar sus productos derivados de las frutas de mayor producción, hecho que ejecutaron empezando con la Capacitación de los comuneros y aprendieron por eso fue sostenible hasta hoy lo hacen sobre todo las mujeres. El trabajo fue participativo y organizado todos los comuneros de manera equitativa participaban en las tareas de la comunidad, hasta que se malogró una pieza del motor de la planta donde se procesaba la transformación de las frutas y los comuneros no se interesaron en comprar los accesorios para arreglar o comprar el motor y hasta la actualidad está paralizada. 
Los hijos de los comuneros asisten a capacitarse a Lima y lo hacen de manera particular individual, es por su propia iniciativa, quieren aprender a competir con el mercado a través de la mejora de la calidad de sus productos que ofrecen. Son dos o tres comuneros de 35 años, padres de familia que se dedican a la agricultura porque les ha trasladado su mamá toda la responsabilidad de la producción de los derivados de las frutas.

En realidad, carecen de la asistencia técnica adecuada de parte de instituciones del Estado para realizar los cambios necesarios. Ante ello, la comunera la pionera de hacer las mermeladas de frutas, la Sra. Jovita, de 65 años de edad, expresa:

He tenido que hablar con mi hijo y decirle ya he trabajado mucho, tú estás sin trabajo ahora te doy todas las cosas para que te hagas cargo de hacer el vinagre, pero debes ir a Lima a enterarte a aprender bien para hacer un buen producto todo depende de ti, eso si yo te voy ayudar a vender.

El Instituto Nacional de Estadística e Informática (INEI, 2013) como muestran las cifras del último Censo Nacional Agropecuario (CENAGRO):

De los más de dos millones de productores rurales, la gran mayoría sigue teniendo un acceso muy restringido al mercado de servicios financieros y de asistencia técnica por parte del Estado. Alrededor del $90 \%$ de productores agropecuarios no recibe asistencia técnica y el $92 \%$ no accede a líneas de crédito. Entre otros factores, esta situación explica la baja productividad y la pobreza que, como hemos visto, afecta al $53 \%$ de los hogares rurales.

Con todo ello, la pequeña agricultura continúa cumpliendo un rol importante en la economía de las familias que habitan las zonas rurales, pero el tamaño de las unidades agropecuarias, cada vez más pequeñas, es una de las variables que guarda relación con el hecho de que las estrategias del productor deban diversificarse. A ello se suma la dificultad para acceder a créditos y la falta de una institucionalidad que permita gestionar a los actores rurales mayores recursos -incluyendo asistencia técnica, riego tecnificado, etcétera- para mejorar su producción y productividad. (p.11)

Promover el acceso de los comuneros productores a servicios de asistencia técnica apropiada a sus necesidades proporcionándoles conocimientos para la innovación en sus cultivos y ser productores en cadenas productivas basados en la experiencia es lo que está ausente.

Otro factor que impide que los agricultores de la comunidad puedan explotar todo su potencial, es la poca disponibilidad de mecanismos de financiación adecuados. Para otorgarles crédito imponen normas y requisitos que no corresponden con la realidad de los agricultores pequeños sin ahorros, les resulta imposible acceder a las garantías de préstamo. Es así que los comuneros agricultores, y las mujeres tienen menor acceso al crédito es más difícil para ellas que contribuyen a la economía familiar con su trabajo comercializando sus productos, esto contribuye a una mayor pobreza en los hogares liderados 
por mujeres. Lejos de aplicar la Teoría The Big Push (el gran empujón) les dificulta salir de ese estado situacional y no logran su bienestar ni desarrollo. Al ver pocas oportunidades en la agricultura muchos jóvenes migran a zonas urbanas en busca de mejores oportunidades ya que hasta ahora no son atraídos para permanecer en su zona rural.

\section{Discusión}

Nuestro estudio sobre Las dinámicas de comercialización de frutas en la comunidad de Cochahuayco: oportunidades y retos para la agricultura familiar campesina, demostró respecto a las dinámicas de comercialización que existe una constante para ellos comunes y son tres: Comercialización IndirectaLarga, Comercialización Indirecto-Corto y Comercialización Directo-Consumidor, que es la más usual les permite vender de inmediato a los visitantes turistas y pueden recuperar sus costos y generarles un ingreso a la familia, estas dinámicas de comercialización tienen una similitud al escenario ecuatoriano donde es el Sistema de Comercialización Directo-Consumidor. Este sistema se caracteriza porque el productor se vincula de forma directa al consumidor final, sin depender de algún otro agente directo para su comercialización, es decir su primer agente de transacción es el consumidor final. La dinámica más interesante en este sistema es que el mismo productor es el encargado de darle un valor agregado a su producto para ser ofertado con mayor oportunidad a este agente, este valor agregado puede ser: mejoramiento de la presentación, cantidad adecuada, producción orgánica (p.26)

Como se indicó ya, la mayor parte de las mujeres de Cochahuayco mostraron un patrón idéntico, respecto al reto de la economía familiar sugiriendo que tiene el potencial necesario para aumentar la oferta de alimentos y mejorar las condiciones de vida de las poblaciones rurales así pueden salir del círculo vicioso de la pobreza, al círculo virtuoso, pero es un tanto lento. Existe una coincidencia con lo que plantea el Centro de Investigación y Desarrollo Tecnológico para la Agricultura Familiar (CIPAF, 2017) en Argentina, cuando señala: "La agricultura familiar contribuye a la creación de empleo, la conservación de los recursos naturales y de la biodiversidad, la preservación cultural, la diversidad multiétnica y la erradicación de la pobreza rural es cada vez más valorada" (p. 18).

En la presente investigación, estudios adicionales, que se refieren a la comercialización, nos permite señalar ciertas similitudes que presenta el resultado encontrado por UBA (2017) cuando señala que la comercialización es el "conjunto de funciones que se desarrollan desde que el producto sale del establecimiento de un productor hasta que llega al consumidor, a través de un mercado determinado" (p. 5).

Es precisamente lo hallado en la Comunidad de Cochahuayco al ver a las mujeres que se dedican a la cosecha de sus frutales y luego dedicarse a la transformación de estos, el objetivo es venderlos, inician 
sus tareas de arreglar sus puestos de expendio, exhibir sus productos como el vinagre, frugos, mermeladas, dulce de membrillo, cuñas, helados y al llegar los visitantes les compren. Es decir, procuran hacer la venta final, es una de las dinámicas de comercialización que les permite vender de inmediato y obtener sus ganancias.

Es un mecanismo de coordinación para las transferencias e intercambios que realizan los diferentes agentes que participan en una cadena productiva. Es lo que en sus actividades diarias hacen los comuneros y comuneras para así satisfacer sus necesidades inmediatas

Estas actividades comerciales realizadas por los comuneros tienen un objetivo, contribuir a la generación de ingresos para la economía familiar y tanto el varón como la mujer juntos complementan el ingreso de la familia y así logar el desarrollo de la familia, coincide en ese sentido la conceptualización que en la data los comuneros hacen en la práctica. Al respecto, Chayanov (como se citó en la FAO, 2014) precisa:

Parte del supuesto de que la economía campesina tiene un carácter familiar, señalando que la organización de la economía campesina está determinada por “la composición de la familia del campesino, su coordinación, sus demandas de consumo, y el número de trabajadores con que cuenta" (p.18).

Efectivamente la familia se organiza para trabajar y a cada uno de los integrantes se asignan funciones específicas, pero es la mujer la que participa activamente en relación a los demás integrantes de la familia, ella afronta los retos y quien tiene una visión para las oportunidades, aunque muchas veces no las puede aprovechar, pero le sirven como experiencia para superar otros retos que se vuelvan a presentar, en este sentido es importante señalar que para cumplir con sus funciones de reproducción/producción en la unidad doméstica campesina, la mayoría de las mujeres entrelazan los quehaceres sociales con los tradicionalmente asignados y los referidos a la producción agropecuaria; de ahí que sus actividades difícilmente se encuentren aisladas, aunque cada una sea realizada en espacios y tiempo separados. Entrelazándolas, se le puede ver en la casa, cultivando el huerto, elaborando artesanías, criando animales de traspatio o llevando alimentos preparados a la parcela. Se les puede ver, incluso, no sólo procesando los alimentos, sino buscándolos, adquiriéndolos, a veces hasta almacenándolos, al tiempo que comercializan otras mercancías para generar ingresos. En muchas ocasiones, también se les ve realizando actividades asignadas por la comunidad y para la comunidad, lo que todavía aumenta más su carga de trabajo.

Las dinámicas de la comercialización están relacionadas con la falta de capacitación y asistencia técnica a los agricultores, están desfasados en cuanto a conocimientos técnicos o el uso de tecnología como herramientas para estar con conocimientos frescos y así elevar la productividad. Al no existir ni establecer alianzas con organismos públicos y privados, capaces de capacitarlos de manera científica - 
tecnológica para satisfacer la demanda con innovaciones en esta nueva etapa de desarrollo productivo y empresarial que ocurrirá en la Cuenca del Rio Lurín. En relación con lo planteado encontramos una similitud con lo que considera CEPAL (2000) "está asociada a la carencia del capital humano necesario para acceder a ciertos empleos, o a la falta de capital financiero, tierra y conocimientos gerenciales y tecnológicos para desarrollar una actividad empresarial” (p. 83).

Respecto a las cadenas productivas de manera empírica los comuneros agrícolas las desarrollan a medida que van realizando los procesos de transformación y la comercialización de sus productos que van a parar a la mesa de los consumidores, para ayudar a establecer un entendimiento común es que las frutas que producen son grupos de alimentos que el organismo de un ser humano necesita para nutrirse, como dicen sobre la cadena alimentaria.

En nuestra investigación no se ha puesto énfasis en las cadenas productivas agroindustriales que suministran todos los materiales para la transformación de las frutas, que es interesante a su vez haberlo considerado puesto que permiten toda una organización y planificación de cómo se debe realizar la comercialización y sobre todo como son sus dinámicas. Por ello le damos una mirada a lo que señalan los autores que citamos.

Calderón y Lario (como se citó en Salazar et al. (2005) afirman que "en las Cadenas Productivas Agroindustriales, se presenta una red de compañías que realizan funciones de suministro de materiales, transformación de estos materiales en productos intermedios o acabados y la distribución de estos productos acabados para los clientes" (p. 45).

\section{Conclusión}

Se puede concluir frente a las consideraciones anteriores que:

Los comuneros agricultores de la Comunidad de Cochahuayco se mantienen operativos por ser la agricultura su actividad prioritaria, esto ha permitido seguir explotando sus tierras de cultivo gracias a una combinación de factores, donde merece destacarse la unión a pesar de sentirse excluidos por las autoridades local, regional y nacional.

Para comercializar sus frutas y derivados cuentan con dinámicas de comercialización que les permiten vender sus productos que son la fuente de su ingreso, y a través de estas cuentan con un mercado fiel, además de ser el turismo que atrae a sus consumidores y no solo venden frutas y sus derivados, las mujeres ofrecen artesanía del lugar que son elaboradas por ellas con esto complementan sus ingresos. La producción de frutas y venta directa e indirecta garantizada por un conjunto de actores constituyen una alternativa a la producción convencional y cadenas productivas para consolidar la agricultura 
campesina económica, social y agroecológicamente sostenibles y así aportar a la soberanía alimentaria de las familias en sus territorios y la lucha contra la pobreza.

\section{Referencias}

Ander-Egg, E. (2005). Metodología y práctica del desarrollo de la comunidad. 2a.. Edición. Editorial Lumen Humanitas.

Alonso, J., Pérez, A., Rivero, R., Romero, E. y Riera, VCM. (2004). El Autodesarrollo Comunitario. Crítica a las mediaciones sociales recurrentes para la emancipación humana. Editorial Feijoo.

Barrantes, R. (2000). Investigación. Un camino al conocimiento. EUNED.

Comisión Económica para América Latina y el Caribe [CEPAL]. (2000). Equidad económica y ciudadanía.

Centro de Investigación y Desarrollo Tecnológico para la Agricultura Familiar [CIPAF] (2017). CIPAF 10 años. Memoria institucional y experiencias de investigación acción participativa con la agricultura familiar. 1a ed. Ediciones INTA.

Caldentey, P. y De Haro, T. (2004). Comercialización de productos agrarios. Mundi Prensa Libros.

Organización de las Naciones Unidas para la Alimentación y la Agricultura [FAO]. (2014). Agricultura Familiar en América Latina y el Caribe.

http://www.fao.org/fileadmin/user_upload/AGRO_Noticias/docs/politicasafresu.pdf

FAO (2017)

Foro Nacional de Agricultura Familiar [FONAF]. (2006). Documento elaborado por las Organizaciones representativas del sector productor agropecuario familiar. Edit. Federación Agraria.

Grupo Temático Comercio con Justicia Honduras. (2011). La comercialización campesina y sus desafíos Experiencias, lecciones y herramientas de comercialización de productos campesinos agroindustriales. https://bit.ly/2UWiOGq

Instituto Nacional de Estadística e Informática. (2013). Censo Nacional Agropecuario 1994. INEI. 
Instituto Interamericano de Cooperación para la Agricultura [IICA]. (2007). La importancia de la agricultura familiar en la república argentina. IICA.

Instituto Interamericano de Cooperación para la Agricultura [IICA] (2018). El Mercado y la Comercialización. (http://creativecommons.org/licenses/by-sa/3.0/igo/)

Ley General de Comunidades Campesinas. Ley 24656 (publicada en 1992 el 09 de diciembre).

Congreso de la República del Perú. Diario Oficial El

Peruano.http//www2.congreso.gob.pe

Martínez, M. (1989). Comportamiento humano: nuevos métodos de investigación. Editorial Trillas.

Organización de las Naciones Unidas [ONU]. (1997). Informe sobre la Pobreza en América Latina. Edit. Centro Regional de Servicios para América Latina y el Caribe, PNUD.

Ramió, C. (2012). Teoría de la organización y administración pública. Editorial Tecnos.

Salazar, F., Cavazos, J. y Vargas, G. (2013). Logística Humanitaria: Un enfoque del Suministro desde las Cadenas Agroalimentarias. Información Tecnológica. https://doi.org/10.4067/S0718-07642014000400007

Taylor, J y Bogdan, R. (1986). Introducción a los métodos cualitativos de investigación: la búsqueda de significados. Editorial Paidós.

Universidad de Buenos Aires, Argentina [UBA]. (2017). Desarrollo y gestión de microemprendimientos en áreas rurales. Módulo 4: Comercialización. http://bit.ly/2keQxJ6.

Fuentes de financiamiento

La investigación fue realizada con recursos propios.

Conflictos de interés

No tiene ningún conflicto de intereses.

Correspondencia

zgonzalez@unfv.edu.pe 